reason, and also because the spectroscopic method, by giving vibration frequencies, supplies direct information about the internal forces, this method has been recently pursued by Angus, Bailey, Wilson and others ; and it has been employed in relation not only to ordinary benzene, but also to benzenes in which a part or the whole of the hydrogen is present in the form of deuterium.

This use of deuterium greatly increases the amount of information obtainable from the spectra; for isotopic substitution leaves the whole force-system of the molecule unchanged, wherefore the vibrations which are responsible for the observed frequencies can be identified by comparing the frequency shifts caused by isotopic substitution with those calculated from the known changes of atomic mass under the assumption of unaltered forces (Teller). Four spectra are studied : Raman scattering, infra-red absorption, ultra-violet fluorescence, and ultra-violet resonance emission. All give information concerning the molecular form and vibrations of the ground state of the molecule. Five benzenes have been examined moderately completely, whilst two others (formulæ in parentheses) are under examination: $\mathrm{C}_{6} \mathrm{H}_{6}$, $\mathrm{C}_{6} \mathrm{H}_{5} \mathrm{D}, \quad 1: 4-\mathrm{C}_{6} \mathrm{H}_{4} \mathrm{D}_{2}, \quad 1: 3: 5-\mathrm{C}_{6} \mathrm{H}_{3} \mathrm{D}_{3}$, (1:2:4:5$\left.\mathrm{C}_{6} \mathrm{H}_{2} \mathrm{D}_{4}\right),\left(\mathrm{C}_{6} \mathrm{HD}_{5}\right), \mathrm{C}_{6} \mathrm{D}_{6}$.

By a comparison of frequency shifts and other spectroscopic characteristics amongst the spectra of these compounds, the frequencies of a large number of vibration-forms have been identified. From this information, with the aid of spectroscopic rules which depend ultimately on a consideration of the physical mechanism of production of the various spectra, it is possible unequivocally to establish the plane, regular model for the isolated (gaseous) benzene molecule. The previously claimed contrary indication is explained as due to the use (or accidental presence) of liquid, wherein the intermolecular forces are sufficient to deform the molecules to a spectroscopically significant extent. An approximate specification of the internal forces could be made at present, but in order to render such a specification complete with respect to harmonic forces, we require further identified frequencies, wherefore the $e$ xtension involving $\mathrm{C}_{6} \mathrm{H}_{2} \mathrm{D}_{4}$ and $\mathrm{C}_{6} \mathrm{HD}_{5}$ is necessary.

\title{
A Stone Age Rock-Shelter in South Africa
}

$\mathrm{O}^{\mathrm{A}}$ AKHURST rock-shelter, situated in an enclosed valley on a farm thirteen miles east of the town of George, Cape Province, South Africa, four miles from the Indian Ocean, and two from the coastal lakes, has been excavated by Mr. A. J. H. Goodwin (Trans. R. Soc. S. Africa, 25, 3 ; 1938). Between February 1932 and February 1935, six visits were paid to the cave, varying in duration from a month to a week, during which the excavation was carried out.

The shelter, which is some sixty feet in length and about twenty-five feet deep at surface level, is divided into two parts. Of these, the inner is separated from the outer and southern portion by a hanging buttress of rock. There is a talus on the southern and eastern sides. The inner portion of the shelter has been left undisturbed for future examination. It is anticipated that much richer deposits will be found here, judging from the midden material which had washed out under the buttress. The outer portion has been excavated down to the base of the deposits. These were of considerable thickness, the total depth excavated being one hundred and twenty-six inches.

The shelter is situated in a dense forest, about twenty feet above a stream in a high sandstone overhanging cliff of sehistose quartz-bearing sandstone. It is approached by an old elephant path. Nearby were rock paintings in red, partially obliterated and not clear enough to photograph, and game pits.

A large amount of skeletal material was found in the deposits. The bones had been much disturbed by root action; while digging for subsequent interments had frequently interfered with earlier burials. It was, therefore, possible to distinguish with certainty eighteen graves only. There had been many more, but the contents were commingled, and at times it was difficult to distinguish grave furniture from introduced material. The skeletal remains had also suffered much from the pressure of gravestones. The greater number of burials occurred at a depth of between fifty and sixty inches from the surface, while a space of some seven by five feet included more than half the graves. As the later people buried at a depth of thirty inches, and the earlier at a depth of fifteen inches only, the graves for the most part occurred at approximately the same level.

The major part of the deposits consists of decayed vegetable matter with a high percentage of wood ash. In addition there are vast quantities of shell present throughout the deposit, this in the upper layers constituting a great part of the bulk. Until the deposits had been built up to some height the shelter could not have afforded much protection against the weather. Hence in the early layers there is evidence of temporary occupation only-the remains of onenight fires and burnt bones. With the advent of Smithfield $B$ man, occupation takes on a more permanent character. The prevailing stone used by all the occupants of the cave was white quartz, probably from a vein of quartz, one hundred yards away, which has been quarried. Chalcedony and agates were also used, brought from neighbouring beaches.

The uppermost three feet of the deposit consists generally of Wilton material. In the top nine inches only was pottery, below this at a depth of thirty-six inches was a normal Wilton culture, in which stone crescents in white quartz and chalcedony are common. Following this short normal phase (that is, above it), comes a long period in which shell crescents (Mytillus edulis), the first shell implements to be described in South Africa, take the place of stone. Apart from this diversion from stone to shell, there is little change, save for the addition of pottery in the latest phase.

Among the ornaments nacre was rare; but vast numbers of ostrich-shell beads were retrieved. In addition there was a single cowrie shell, and a number of naturally bored shells had been brought to the cave, presumably for ornaments. A hippopotamus tusk and one ivory bead were found, as well as 
borers, arrow points, and tubes of bone. Fish bones, scarce at the beginning of this period, were found in large quantities in later levels, pointing to the development of a considerable competence in fishing. Banked ash at the southern end indicated a protection fireplace, dividing the cave shelter into two compartments, one for general purposes and one for sleeping.

Below the thirty-six inch level Smithfield $C$ material extends down to a depth of sixty inches, the richest level being between thirty-six and fifty-four inches. Throughout the deposit only implements of the general scraper type could be recognized with certainty. More than five thousand scrapers in white quartz were collected from the Smithfield deposit. There were as well two hundred flakes of brown chalcedony. The quartz flakes, almost a solid mass, in parts up to two feet in depth, indicated that the shelter at this period must have been a workshop. Throughout this deposit ostrich shell beads in large numbers were found, but nacre ornaments are rare.

At the base of the Smithfield $C$ deposit between two buffer layers was a carbon floor or layer, representing a period of peculiarly fierce forest fire, which was presumably the cause of the desertion of the cave by the Smithfield $B$ people. The Smithfield $B$ culture extended from a depth of sixty inches down to seventy-seven inches or more in parts. It is to be remarked that there is no great difference to be observed between the implements from above and below the carbon floor. The variation is rather one of size, or in distribution of sizes. The scrapers, for example, are much larger. All implements are still of the general scraper family. The deposit as a whole is far less rich than the Smithfield $C$ layer and represents the normal debris of a home site. The major part of the material is quartz, chalcedonic quartz being rare and brown chalcedony absent. One end scraper is of fossilized wood from the Tertiary Enon beds. A Mossel Bay point and a Still Bay type mark the overlying deposit as post-dating the "Cape Flats complex".

Below seventy-seven inches evidence of the sterile charaeter of the lower deposits begins to become apparent. In one section a few good Smithfield $B$ specimens still appear between the eighty-four and ninety inch levels; but below ninety-six inches formal implements disappear. In the underlying material there are only scattered hearths with burnt bones and quartz split by fire or broken by man, but no implement types that could be recognized. Though there are suggestions of Middle Stone Age technique on some of the flakes, these must be ignored, as deduction from the sugary quartz would be impossible to maintain. There is, however, evidence to show that use was made of the shelter for a very considerable period before Smithfield $B$ man appears.

The pottery has been submitted to a careful and detailed analysis by Mr. J. F. Schofield, who terms it "Hottentot", and suggests that its specific characters, lugs and an occasional oval section, are an adaptation to the use of the pack-ox by a nomadic people.

The skeletal material has been studied by Prof. M. R. Drennan, whose detailed report deals with the relation of the Oakhurst people to the Wilton race and the Hottentot. The skeletal material shows that these people had many Bushmen characters, but they were of a special type, being much taller and more robust, with bigger heads. They resembled the type to which the term 'Hottentot' has been applied-a term which accordingly has to be defined (see NATURE, p. 1146). The main conclusion is that the Boskop type must be regarded as the ancestor of the Hottentot. The infantile material, which is the first series of any extent to be examined systematically, has provided data for a study of growth in infancy.

\section{Submarine Light Measurements}

$\mathrm{A}^{\mathrm{T}}$ $T$ the meeting of the International Council for the Exploration of the Sea held at Copenhagen on May 23-28, a special session was devoted to submarine light measurements. H. H. Poole gave a brief summary of the results obtained by different workers on the variation of surface loss with weather conditions, pointing out the difficulties involved and stressing the importance of further work on the effect of surface conditions on the angular distribution of submarine daylight.

H. Pettersson described the work of himself and his co-workers on the angular distribution at depths of 5 and $10 \mathrm{~m}$. below a smooth water surface. Their measurements showed that, with the sun shining, the illumination was chiefly concentrated within a comparatively small solid angle round the calculated path of a ray of sunlight, as refracted by a smooth surface, the direction of maximum illumination being slightly nearer the vertical at $10 \mathrm{~m}$. than at $5 \mathrm{~m}$. From these results it is possible to calculate the ratio of the total illumination (as measured by a photometer with a spherical receiving surface) to the vertical illumination (as recorded by a plane photometer with its window horizontal). This is important, since the former is the governing factor in photosynthesis, and the latter is usually measured. The values found for the ratio total/vertical ranged from about 1.5 with the sun at $20^{\circ}$ altitude to 1.35 with diffuse daylight.

M. Graham described measurements of the opacity of the water at 44 stations in the North Sea made by $(a)$ the Lowestoft absorption photometer, $(b)$ measurements of the percentage of daylight at a depth of $10 \mathrm{~m}$., and $(c)$ Seechi's disk. For finding the origin and history of the water masses involved he considers that the use of Seechi's disk has much to recommend it, but that the most promising method is that of Pettersson's transparency meter, in which an artificial light source and a photo-electric cell are used at any required depth.

E. K. Gabrielson and E. Steemann Nielsen reported experiments on the photosynthesis of various diatoms in light of different colours. Their results showed that for a given amount of energy violet-blue light produced about twice as great assimilation of carbon dioxide as either yellow-green or orange-red, the latter spectral regions being about equally efficient.

The special sub-committee on the standardization of photo-cells for daylight measurements held several meetings, and hopes soon to be in a position to undertake this standardization in energy units for different spectral regions. 